\title{
Design and construction of a heat stage for investigations of samples by atomic force
} microscopy above ambient temperatures

\author{
Bækmark, Thomas Rosleff; Bjørnholm, Thomas; Mouritsen, Ole G.
}

Published in:

Review of Scientific Instruments

Link to article, DOI:

$10.1063 / 1.1147849$

Publication date:

1997

Document Version

Publisher's PDF, also known as Version of record

Link back to DTU Orbit

Citation (APA):

Bækmark, T. R., Bjørnholm, T., \& Mouritsen, O. G. (1997). Design and construction of a heat stage for investigations of samples by atomic force microscopy above ambient temperatures. Review of Scientific Instruments, 68(1), 140-142. https://doi.org/10.1063/1.1147849

\section{General rights}

Copyright and moral rights for the publications made accessible in the public portal are retained by the authors and/or other copyright owners and it is a condition of accessing publications that users recognise and abide by the legal requirements associated with these rights.

- Users may download and print one copy of any publication from the public portal for the purpose of private study or research.

- You may not further distribute the material or use it for any profit-making activity or commercial gain

- You may freely distribute the URL identifying the publication in the public portal 


\title{
Design and construction of a heat stage for investigations of samples by atomic force microscopy above ambient temperatures
}

\author{
Thomas Rosleff Baekmark ${ }^{\text {a) }}$ \\ Department of Chemistry, The Technical University of Denmark, DK-2800 Lyngby, Denmark \\ Thomas Bjørnholm ${ }^{\text {) }}$ \\ Centre for Interdisciplinary Studies of Molecular Interactions, CISMI University of Copenhagen, \\ Fruebjergvej 3, DK-2100 Copenhagen $\varnothing$, Denmark \\ Ole G. Mouritsen ${ }^{\mathrm{c})}$ \\ Department of Chemistry, The Technical University of Denmark, DK-2800 Lyngby, Denmark
}

(Received 17 June 1996; accepted for publication 13 September 1996)

\begin{abstract}
The construction from simple and cheap commercially available parts of a miniature heat stage for the direct heating of samples studied with a commercially available optical-lever-detection atomic force microscope is reported. We demonstrate that by using this heat stage, atomic resolution can be obtained on highly oriented pyrolytic graphite at $52{ }^{\circ} \mathrm{C}$. The heat stage is of potential use for the investigation of biological material at physiological temperatures. (C) 1997 American Institute of Physics. [S0034-6748(97)00801-0]
\end{abstract}

\section{INTRODUCTION}

The experimental techniques of scanning tunneling microscopy $(\mathrm{STM})^{1}$ and atomic force microscopy $(\mathrm{AFM})^{2}$ have, apart from their great usefulness in material sciences in general, ${ }^{3}$ proven to be very powerful tools for the investigation of biological material at the molecular level, ${ }^{4-8}$ for the study of model systems of biological membranes on length scales over several orders of magnitude, ${ }^{9-17}$ and for the direct study of living cells. ${ }^{18}$

One of the present limitations to achieving increased knowledge on the behavior of biological molecules in vivo and in vitro by use of AFM or STM is the inability of commercially available microscopes to operate at temperatures different from ambient temperature. Several attempts have been made by different investigators to overcome this hurdle. ${ }^{13,19-22}$ The most direct solution to the problems involved in performing AFM microscopy above ambient temperatures is to change the ambient temperature (i.e., to place the microscope in an insulated box) and then operate the microscope at the desired temperature after thermal equilibrium has been established. This method has successfully been applied by several groups ${ }^{19,20,22}$ to samples studied by $\mathrm{AFM}$ at temperatures from $6 \mathrm{~K}$ up to room temperature, but has so far been unsatisfactory when studying samples above room temperature. ${ }^{5,20,23}$ Among other reasons, this may be due to the fact that the loading forces vary due to thermally induced cantilever drift. ${ }^{5,23}$ Furthermore, the signal-to-noise ratio may be too small ${ }^{20}$ for operating the AFM with satisfactory resolution, and the electronic components of the AFM may in some cases not be designed to operate at temperatures elevated even just slightly $\left(<40^{\circ} \mathrm{C}\right)$ above room

${ }^{a)}$ Present address: Lehrstuhl für Biophysik, E22, The Technical University of Munich, James-Frank-Strasse, D-85748 Garching, Germany; Electronic mail: tbaekmar@physik.tu-muenchen.de

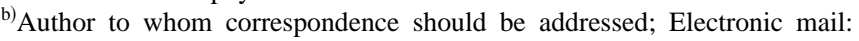
tb@symbion.ki.ku.dk

${ }^{c)}$ Associate fellow of the Canadian Institute for Advanced Research; Electronic mail: ogm@fki.dtu.dk temperature (personal communication with Leif Sørensen of Danish Micro Engineering-DME).

Attempts have also been made to solve the problem of thermostating through direct heating of sample and tip, leaving the scanning microscope to operate at room temperature. With STM, direct heating has proved to be a powerful tool for imaging surfaces with atomic resolution, ${ }^{21}$ giving rise to a new type of scanning microscope, the scanning thermopower microscope (SThM), that recently allowed Poler et al. ${ }^{13}$ to image monolayers of guanine on mica at $72{ }^{\circ} \mathrm{C}$.

With the AFM, direct heating has been attempted by several groups. A system based on the circulation of thermostated water in a fluid-cell AFM, has been proposed by Kipp et al. ${ }^{24}$ and the problem of temperature control in the fluid cell has been discussed by the same authors. ${ }^{25}$ Furthermore, several successful attempts by different authors to convert the AFM into an atomic force SThM by modifying the cantilever have been reported. ${ }^{26-31}$ In this setup, heating occurs either through the tip ${ }^{30,31}$ or by direct sample heating. However, at present the lateral resolution using atomic forces SThM lies on the scale of micrometers with both heating methods, which is in contrast to the atomic resolution obtainable with the tunneling SThM. ${ }^{32}$

We here report on the design and construction of a heat stage to be used together with a commercially available AFM (we used a Rasterscope 4000 from DME) for direct heating of sample and cantilever. Atomic resolution at elevated temperatures is demonstrated by imaging highly ordered pyrolytic graphite (HOPG) with atomic resolution at $52{ }^{\circ} \mathrm{C}$.

\section{INSTRUMENTATION}

A miniature electrical heating-stage was used to heat the samples (Fig. 1). The central heat generating element is an ohmic resistance ( 220 or $100 \Omega$, both allowing for a maximum temperature of $90^{\circ} \mathrm{C}$, when connected to an external variable current supply, Mascot Type 719, Norway) encapsulated in gold-covered iron and kept in place with thermo- 


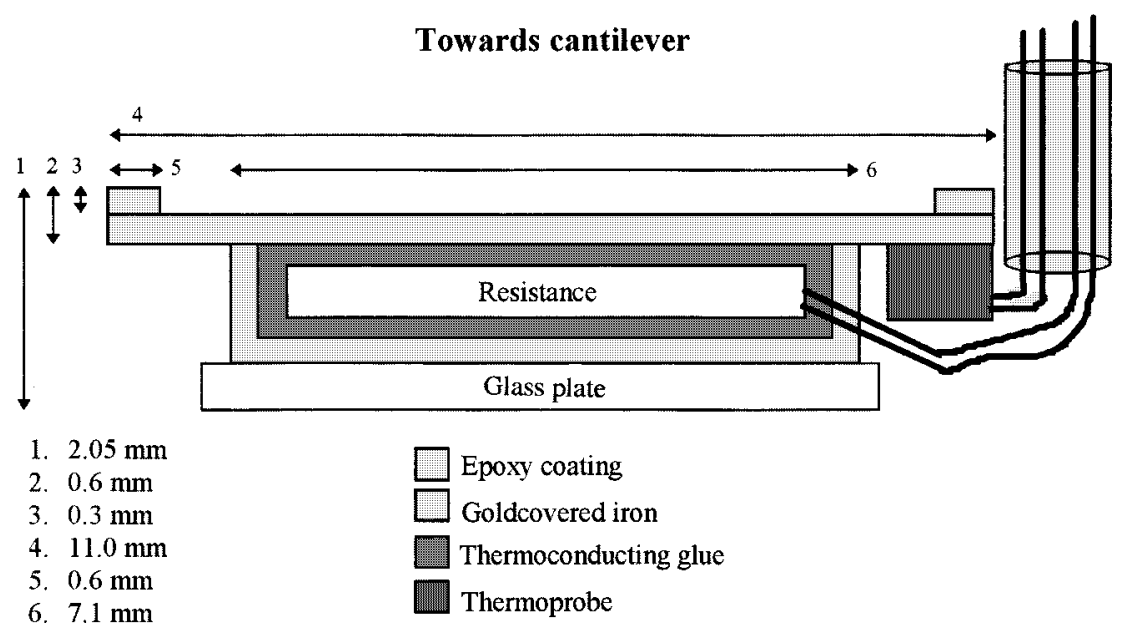

FIG. 1. Schematic drawing of the heat stage.

conducting glue. To the iron capsule we have attached a thermoprobe, a Pt100 thermoresistor (Standard B.S. 1904), which allows us to monitor the temperature of our sample to within $\pm 0.5 \mathrm{~K}$. Also attached is a glass plate at the bottom of the heat stage to (partially) decouple the heat stage thermally from the piezoelement. The two sets of electrical wires leading away from the heat stage are enclosed in an epoxy coating and lifted $0.5 \mathrm{~cm}$ up above the heat stage in order to keep the wires from touching the cantilever slide. This was done in order to keep vibrations in the piezoelement from inducing surplus cantilever vibrations.

\section{EXPERIMENT}

HOPG was purchased from DME and cleaved shortly before use. For imaging we used a Rasterscope 4000 from DME and microfabricated $\mathrm{Si}_{3} \mathrm{~N}_{4}$ cantilever tips with nominal spring constants of either 0.36 or $0.08 \mathrm{~N} / \mathrm{m}$. The images ( 256 pixels $\times 256$ pixels) were recorded in air at different temperatures in contact mode at a constant force of $1 \mathrm{nN}$. Good thermal contact between sample and heat stage was assured by use of a thermoconducting silicone grease, Dow Corning ${ }^{\mathrm{TM}}$ heat sink compound 340 (Dow Corning Corp., USA.)

Tip and sample were brought into contact and the AFM was adjusted to give good images of the surface before heating of the samples. During heating the AFM was continuously readjusted to compensate for the thermal drift of the tip induced by the heating. Typically the system would become stable at the new temperature within the time span of $1 \mathrm{~h}$. Measurements were not initiated until both cantilever and temperature had remained stable for at least $15 \mathrm{~min}$.

During measurements, we monitored the ambient temperature through a second thermoprobe at a distance of $1 \mathrm{~cm}$ from the heat stage. We found that the ambient temperature did not increase more than about $1 \mathrm{~K}$ within the time span of hours. Thus we are confident that the electronic parts of the AFM were not influenced by the heating.

\section{RESULTS AND DISCUSSION}

The results of our measurements are shown on the Figs. 2 and 3. Figure 2 shows HOPG with atomic resolution at
$52{ }^{\circ} \mathrm{C}$ and Fig. 3 shows HOPG at the same temperature with a magnification of $1 \times 1 \mu \mathrm{m}$. The insert to Fig. 2 shows the two-dimensional Fourier transform spectrum of the image. We find an interatomic spacing of $2.13 \pm 0.1 \AA$, as expected for graphite (Ref. 33, Table B-198). From the flatness of Fig. 3 , one can conclude that the heating is very homogeneous over the surface of the sample, since any inhomogeneity in temperature would lead to the immediate destruction of the focus due to cantilever drift as discussed by Radmacher et $a l .{ }^{23} \mathrm{We}$ have obtained similar results with the same degree of spatial resolution at other temperatures.

Contrary to the results obtained with the atomic force $\mathrm{SThM}^{26-31}$ we can obtain atomic resolution with the use of the heat stage described above. The following two features are believed to be important: First, since heat conduction through air represents the major mode of heat transfer between sample and tip, ${ }^{29}$ we work the AFM with the cantilever and the sample at thermal equilibrium, which eliminates any major cantilever fluctuations due to thermal drift. Sec-

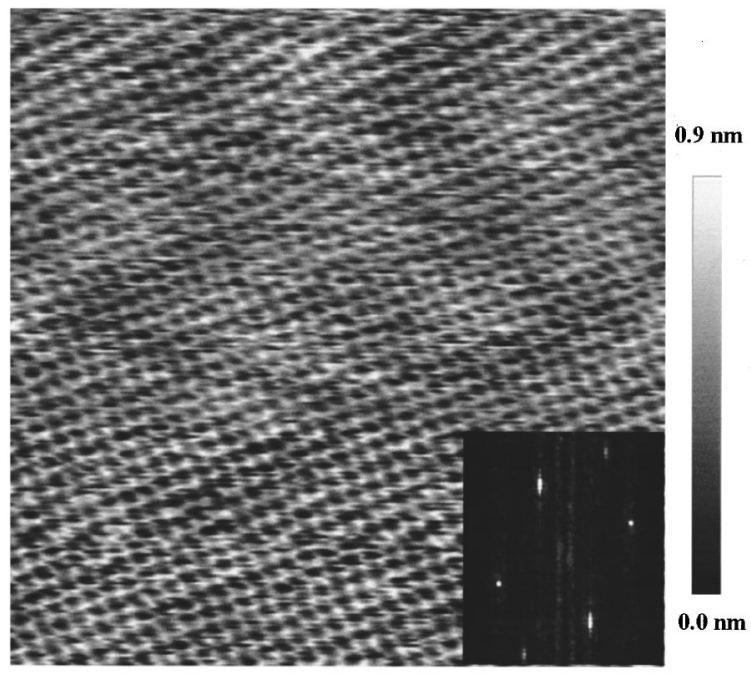

FIG. 2. Image of HOPG with atomic resolution measured at $52{ }^{\circ} \mathrm{C}$ with a lateral resolution of $5.2 \mathrm{~nm} \times 5.2 \mathrm{~nm}$. Scale bar inserted to show roughness. The insert shows the two-dimensional fast Fourier transform of the image. 


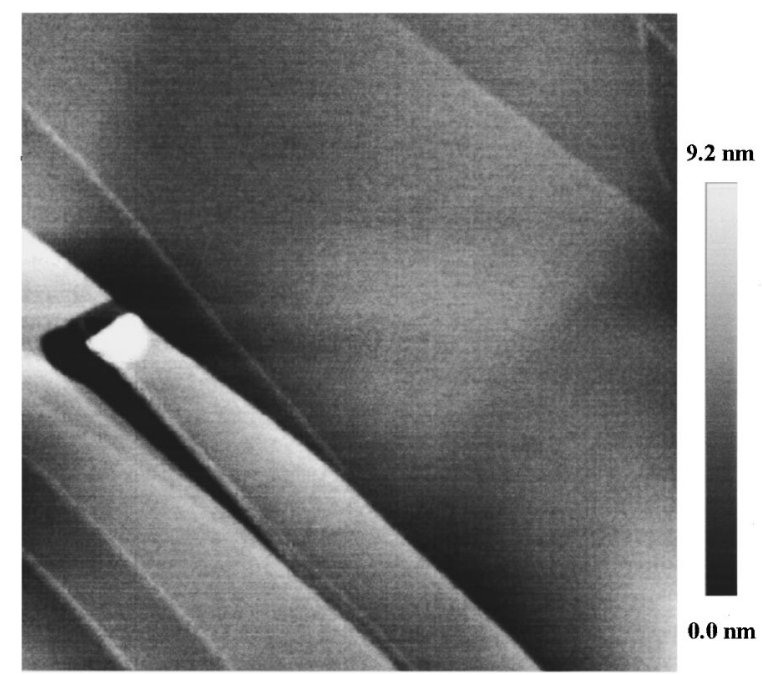

FIG. 3. Image of $\mathrm{HOPG}$ measured at $52{ }^{\circ} \mathrm{C}$ with a lateral resolution of $1 \times 1$ $\mu \mathrm{m}$. Scale bar inserted to show roughness.

ond, since $\mathrm{Si}_{3} \mathrm{~N}_{4}$ tips are poor thermal conductors, ${ }^{27}$ we use such tips while scanning at constant force, assuring that the scans are insensitive to any minor (atomic scale) thermal fluctuations on the sample surface.

Due to its ability to work at temperatures above room temperature, the present heat-stage AFM setup should prove useful for investigation of biological material at physiological temperatures.

Note added in proof: During the publication process of this article, an article by I. Muševič et al. [Rev. Sci. Instrum. 67, 2554 (1996)] corroborating the results described in the present article has appeared.

\section{ACKNOWLEDGMENTS}

The authors wish to thank Glenn E. Nielsen of DME for building the heat stage. Bo J. Nielsen of the Department of Chemistry, The Technical University of Denmark, is thanked for his help in building the thermosensors. This work was supported by the National Science Research Council and the Danish Technical Research Council.

${ }^{1}$ G. Binnig, H. Rohrer, Ch. Gerber, and E. Weibel, Phys. Rev. Lett. 49, 57 (1982).

${ }^{2}$ G. Binnig, C. F. Quate, and Ch. Gerber, Phys. Rev. Lett. 56, 930 (1986). ${ }^{3}$ E. Meyer and H. Heinyelmann, in Scanning Tunneling Microscopy II, edited by R. Wiesendanger and H.-J. Güntherodt, Springer Series in Surface Sciences Vol. 28 (Springer, New York, 1992), p. 99.

${ }^{4}$ M. Egger, F. Ohnesorge, A. L. Weisenhorn, S. P. Heyn, B. Drake, C. B.
Prater, S. A. C. Gould, P. K. Hansma, and H. E. Gaub, J. Struct. Biol. 103, 89 (1990).

${ }^{5}$ M. Fritz, M. Radmacher, J. P. Cleveland, M. W. Allersma, R. J. Stewart, R. Gieselmann, P. Janmey, C. F. Schmidt, and P. K. Hansma, Langmuir 11, 3529 (1995).

${ }^{6}$ H. G. Hansma, A. L. Weisenhorn, A. B. Edmundson, H. E. Gaub, and P. K. Hansma, Clin. Chem. 37, 1497 (1991).

${ }^{7}$ H. G. Hansma, K. A. Browne, M. Bezanilla, and T. C. Bruice, Biochemistry 33, 8436 (1994).

${ }^{8}$ J. Mou, D. M. Czajkowsky, Y. Zhang, and Z. Shao, FEBS Lett. 371, 279 (1995).

${ }^{9}$ C. H. E. Berger, K. O. v. d. Werf, R. P. H. Kooyman, B. G. de Grooth, and J. Greve, Langmuir 11, 4188 (1995).

${ }^{10}$ S. Ge, A. Takahara, and T. Kajiyama, Langmuir 11, 1341 (1995).

${ }^{11}$ J. M. Mikrut, P. Dutta, J. B. Ketterson, and R. C. MacDonald, Phys. Rev. B 48, 14479 (1993).

${ }^{12}$ R. M. Overney, E. Meyer, J. Frommer, D. Brodbeck, R. Lüthi, L. Howald, H.-J. Güntherodt, M. Fujihira, H. Takano, and Y. Gotoh, Nature 359, 133 (1992).

${ }^{13}$ J. C. Poler, R. M. Zimmermann, and E. C. Cox, Langmuir 11, 2689 (1995).

${ }^{14}$ S. J. Stranick, A. N. Parikh, Y.-T. Tao, D. L. Allara, and P. S. Weiss, J. Phys. Chem. 98, 7636 (1994).

${ }^{15}$ Y.-H. Tsao, S. X. Yang, D. F. Evans, and H. Wennerström, Langmuir 7, 3154 (1991).

${ }^{16}$ Y.-H. Tsao, S. X. Yang, and D. F. Evans, Langmuir 8, 1188 (1992).

${ }^{17}$ I. Vikholm, J. Peltonen, and O. Teleman, Biochem. Biophys. Acta 1233, 111 (1995).

${ }^{18}$ M. Fritz, M. Radmacher, and H. E. Gaub, Biophys. J. 66, 1328 (1994).

${ }^{19}$ H. J. Hug, A. Moser, Th. Jung, O. Fritz, A. Wadas, I. Parashikov, and H. J. Güntherodt, Rev. Sci. Instrum. 64, 2920 (1993).

${ }^{20}$ J. Mou, J. Yang, and Z. Shao, Rev. Sci. Instrum. 64, 1483 (1993).

${ }^{21}$ C. C. Williams and H. K. Wickramasinghe, Nature 344, 317 (1990).

${ }^{22}$ C. W. Yuan, E. Batalla, M. Zacher, A. L. de Lozanne, M. D. Kirk, and M. Tortonese, Appl. Phys. Lett. 65, 1308 (1994).

${ }^{23}$ M. Radmacher, J. P. Cleveland, and P. K. Hansma. Scanning 17, 1921 (1995).

${ }^{24}$ S. Kipp, R. Lacmann, and M. A. Schneeweiss, J. Cryst. Growth 141, 291 (1994).

${ }^{25}$ S. Kipp, R. Lacmann, and M. A. Schneeweiss, Ultramicroscopy 57, 333 (1995).

${ }^{26}$ J. Lai, M. Chandrachood, A. Majumdar, and J. P. Carrejo, IEEE Electron Device Lett. 16, 312 (1995).

${ }^{27}$ A. Majumdar, J. P. Carrejo, and J. Lai, Appl. Phys. Lett. 62, 2501 (1993).

${ }^{28}$ A. Majumdar, J. Lai, M. Chandrachood, O. Nakabeppu, Y. Wu, and Z. Shi, Rev. Sci. Instrum. 66, 3584 (1995).

${ }^{29}$ O. Nakabeppu, M. Chandrachood, Y. Wu, J. Lai, and A. Majumdar, Appl. Phys. Lett. 66, 694 (1995).

${ }^{30}$ M. Nonnenmacher and H. K. Wickramasinghe, Appl. Phys. Lett. 61, 168 (1992).

${ }^{31}$ R. J. Pylkki, P. J. Moyer, and P. E. West, Jpn. J. Appl. Phys. 33, 3785 (1994).

${ }^{32}$ The present low lateral resolution is reported (Ref. 29) to be due to low thermal resolution presently of the order of $10^{-1} \mathrm{~K}$. To obtain atomic resolution with the atomic force SThM apparatus, the thermal resolution has to be of the order of $10^{-5} \mathrm{~K}$.

${ }^{33}$ Handbook of Chemistry and Physics, 51st ed., edited by R. C. Weast (Chemical Rubber, Cleveland, 1970-1971), p. 198. 